\title{
Nitric Oxide Synthase Inhibitors Modulate Nerve-Growth-Factor Mediated Activation of Akt
}

\author{
Cheryl L. Cragg, Janet C. MacKinnon, and Bettina E. Kalisch \\ Department of Biomedical Sciences, Ontario Veterinary College (OVC), University of Guelph, Guelph, ON, Canada N1G 2W1 \\ Correspondence should be addressed to Bettina E. Kalisch, bkalisch@uoguelph.ca
}

Received 30 October 2011; Accepted 17 November 2011

Academic Editors: M. Acevedo-Duncan and Z. Pan

Copyright () 2012 Cheryl L. Cragg et al. This is an open access article distributed under the Creative Commons Attribution License, which permits unrestricted use, distribution, and reproduction in any medium, provided the original work is properly cited.

\begin{abstract}
Nitric oxide (NO) modulates nerve-growth-factor- (NGF-) mediated signaling and gene expression. In the present paper, the role of NO in NGF-mediated Akt activation in PC12 and IMR32 cells was investigated. Cells were treated with NGF (50 ng/mL) in the presence or absence of NO synthase (NOS) inhibitors and Akt phosphorylation assessed by western blot analysis. In both cell lines, Akt was phosphorylated within 15 min of NGF treatment. In PC12 cells, this level of phosphorylation was sustained for 60 min, while in IMR32 cells, the activation decreased after $30 \mathrm{~min}$ of NGF treatment. The nonselective NOS inhibitor $\mathrm{N}^{\omega}$-nitro-L-arginine methylester (L-NAME; $20 \mathrm{mM}$ ) had no effect on NGF-mediated Akt phosphorylation in PC12 cells but in combination with NGF, the iNOS selective inhibitor s-methylisothiourea (S-MIU; $2.0 \mathrm{mM}$ ) maintained Akt phosphorylation up to $2 \mathrm{~h}$. In IMR32 cells, both L-NAME and S-MIU prolonged the activation of Akt. Pretreatment with $50 \mu \mathrm{M}$ U0126, a MAP kinase pathway inhibitor, also increased the activation of Akt in both cell lines. These data suggest that NO modulates the duration of phosphorylation of Akt in response to NGF and that this effect may, in part, be mediated by the effects of NO on the Ras-MAP kinase pathway.
\end{abstract}

\section{Introduction}

Binding of nerve-growth-factor (NGF) to its high affinity receptor (TrkA) elicits a range of cellular responses such as neuronal survival, cell cycle arrest, and phenotypic and morphological differentiation. Stimulation of TrkA receptors activates protein kinases and adaptor proteins in multiple signaling pathways ultimately regulating the expression and activation of transcription factors and other cellular proteins [1]. Activation of one of these pathways, the phosphatidyl inositol triphosphate (PI3) kinase pathway by NGF, propagates a cascade leading to the phosphorylation of Akt (also called protein kinase B; PKB) [1]. Blockade of Akt activation by PI3 kinase inhibitors reveals that activation of this important signaling pathway is required for NGFmediated increases in the levels of the endothelial isoform of the enzyme nitric oxide synthase (eNOS or NOS III) [2]. Interestingly, nitric oxide (NO) plays a role in NGF-mediated neurotrophic response [3-6]. Although activation of both Akt [7-9] and NO [3-6] appears to be required for many of the neurotrophic actions of NGF, the exact link between NO production and the phosphorylation of Akt is not clear.
$\mathrm{NO}$ is synthesized by the nitric oxide synthase (NOS) enzymes [10]. Three distinct genes generate three isoforms of NOS: neuronal NOS (nNOS; NOSI), eNOS, and inducible NOS (iNOS; NOSII). In PC12 cells, NGF increases the expression of all three NOS isozymes $[4,5,11]$ and nitrite production (likely resulting from increased NO synthesis [12]), and cotreatment of cells with NGF and NOS inhibitors attenuates NGF-mediated neurite outgrowth [3-6]. In addition, we have also found that NOS inhibitors attenuate the NGF-mediated enhancement of cholinergic neuronal phenotype, measured as increased choline acetyltransferase (ChAT) activity and steady-state mRNA levels [4] and increases in amyloid precursor protein (APP) levels [3] in PC12 cells. NO has also been linked with components of NGF-TrkA signaling pathways believed to be involved in gene expression and neurite outgrowth. NO can activate p $21^{\text {ras }}$ in human $\mathrm{T}$ cells [13], and NO released from NO donor drugs stimulates the phosphorylation of MAP kinase in hippocampal slices with this activation occurring at the level of Ras protein [14]. Several studies have demonstrated that NO [15-18] and peroxynitrite $[19,20]$ activate $\mathrm{p} 42$ and p44 MAP kinase in a variety of cell culture systems, and we 
reported that NO modulates the NGF-mediated prolonged activation of MAP kinase in a cGMP-independent manner [21]. Similarly, in PC12 cells, NO donor drugs were reported to activate Akt [22]. However, it is not known, whether NO also modulates the NGF-mediated activation of Akt. We therefore investigated the relationship between NGF, NO, and Akt activation. To begin, we established a temporal profile for activation of Akt following exposure of PC12 and IMR32 cells to NGF. Both of these cell lines are NGFresponsive and have been used as cholinergic neuron models [3-7, 23, 24]; however, differences in NGF-TrkA signaling pathway activation could exist. For example, NGF has been reported to increase ChAT levels in PC12 cells, [4, 25-27] this effect has not been described in IMR32 cells. Since NGF increases both $\mathrm{Ca}^{+2}$-dependent and -independent NOS activity [5], we used $\mathrm{N}^{\omega}$-nitro-Larginine methylester (LNAME) as a general NOS inhibitor and s-methylisothiourea (MIU) as an iNOS selective blocker [28] to examine effects of NOS inhibitors on the activation of Akt by NGF.

\section{Methods}

2.1. Materials. Dulbecco's modified Eagle medium (DMEM), minimum essential medium (MEM), horse serum, gentamicin, primers, and reverse transcriptase- (RT-) polymerase chain reaction (PCR) reagents were purchased from Invitrogen (Carlsbad, CA, USA), and fetal bovine serum (FBS) was obtained from HyClone Laboratories (Logan, UT, USA). NGF was obtained from Harlan Bioproducts for Science (Indianapolis IN, USA); L-NAME, S-MIU, sodium pyruvate and mouse monoclonal anti- $\alpha$-tubulin were all purchased from Sigma Aldrich (St. Louis, MO, USA), and the MAP kinase signal transduction pathway inhibitor U0126 was obtained from Calbiochem (San Diego, CA, USA). Rabbit polyclonal phospho-Akt (Ser473) and total Akt antibodies were from New England Biolabs (Ipswich, MA, USA) and nitrocellulose membranes (Hybond-C), sheep anti-mouse IgG and the enhanced chemiluminescence (ECL) kit were obtained from Amersham/GE Health Care (Piscataway, NJ, USA), and the SYBR green reaction mixture was from Qiagen (Mississauga, ON, Canada). All other chemicals were molecular or electrophoresis grade and obtained from Fisher Scientific (Ottawa, ON, Canada) or DiaMed Laboratories (Mississauga, ON, Canada).

2.2. Tissue Culture. $\mathrm{PC} 12$ cells were maintained at $37^{\circ} \mathrm{C} / 5 \%$ $\mathrm{CO}_{2}$ in DMEM containing 5\% FBS, 5\% horse serum, and $50 \mu \mathrm{g} / \mathrm{mL}$ gentamicin. IMR32 cells were housed under similar conditions in MEM containing 10\% FBS, $1 \mathrm{mM}$ sodium pyruvate, and $50 \mu \mathrm{g} / \mathrm{mL}$ gentamicin. To examine NGF-induced activation of Akt in the presence or absence of NOS inhibitors, cells were plated onto $60 \mathrm{~mm}$ CellBind coated plastic culture dishes (Corning; Acton, MA, USA) at a density of $2.0 \times 10^{6}$ cells per plate for $24 \mathrm{~h}$ prior to experiments. NGF and NOS inhibitors were added directly to culture media, and cell lysates were assayed for activation of Akt by western immunoblot analysis, as described below.
2.3. Temporal Profile for NGF-Mediated Activation of Akt. To establish a time course for activation of Akt by NGF, PC12 and IMR32 cells were treated with $50 \mathrm{ng} / \mathrm{mL}$ NGF and harvested at varying times between 15 and $240 \mathrm{~min}$. Untreated cells were used as controls.

2.4. Effects of Inhibitors of NOS and MAP Kinase. The role of NO in the NGF-mediated phosphorylation of Akt was evaluated using the NOS inhibitors L-NAME $(20 \mathrm{mM})$ or S-MIU $(2.0 \mathrm{mM})[3,4]$. In each case, cells were pretreated with inhibitors for 1 to $2 \mathrm{~h}$ prior to the addition of NGF $(50 \mathrm{ng} / \mathrm{mL})$. Levels of phosphorylation of Akt were monitored by immunoblot after the addition of NGF to control and inhibitor-treated cells. Untreated PC12 and IMR32 cells and cells treated with NOS inhibitor in the absence of NGF were used as controls. To evaluate the contribution of MAP kinase activation to the NGF-mediated phosphorylation of Akt, cells were pretreated with $50 \mu \mathrm{M}$ U0126 $1 \mathrm{~h}$ prior to the addition of NGF [3].

2.5. Western Blot Analysis. Control and treated PC12 and IMR32 cells were rinsed with ice-cold phosphate-buffered saline (PBS) and harvested in $250 \mu \mathrm{L}$ of 1x SDS-sample buffer (final concentration: $62.5 \mathrm{mM}$ Tris- $\mathrm{HCl}$; $\mathrm{pH}$ 6.8, 2\% SDS, $10 \%$ glycerol, $41.7 \mathrm{mM}$ DTT, and $0.01 \%$ phenol red) of which 35 (PC12 cells) or $50 \mu \mathrm{L}$ (IMR32 cells) was loaded onto $10 \%$ SDS/polyacrylamide separating gels. Following electrophoresis, proteins were transferred onto nitrocellulose membranes using a semidry transfer unit (Bio-Rad Laboratories Ltd.; Mississauga, ON, Canada) with transfer buffer ( $48 \mathrm{mM}$ Tris, $39 \mathrm{mM}$ glycine, $\mathrm{pH} 9.2$ ) containing $20 \%$ methanol. Membranes were then blocked in 10\% milk and $5 \%$ bovine serum albumin (BSA) in tris-buffered saline (TBS) containing $0.1 \%$ Tween-20 (TBS-T) for $1 \mathrm{~h}$ followed by incubation in 1:1000 rabbit polyclonal phospho-Akt antibody in TBS-T containing 5\% BSA overnight. Antibody detection was achieved using 1:2500 donkey anti-rabbit IgG-horse radish peroxidase conjugated secondary antibody (Amersham) in TBS-T with 5\% BSA for $1 \mathrm{~h}$, followed by ECL. Blots were stripped with $62.5 \mathrm{mM}$ Tris, $\mathrm{pH}$ 6.7, containing $2 \%$ SDS and $100 \mathrm{mM} 2$-mercaptoethanol at $50^{\circ} \mathrm{C}$ for $30 \mathrm{~min}$. Membranes were then rinsed in TBS for at least $4 \mathrm{~h}$ before blocking with $10 \%$ milk and 5\% BSA in TBS$\mathrm{T}$ for $1 \mathrm{~h}$. Blots were probed for total Akt using 1:1000 rabbit polyclonal Akt antibody as described above. Similar protein loading between samples was confirmed by exposing blots to $1: 50000$ mouse monoclonal anti- $\alpha$ tubulin antibody (Sigma Aldrich) followed by $1: 2500$ goat anti-mouse IgGhorse radish peroxidase conjugated secondary antibody, both in $5 \%$ milk in TBS-T.

2.6. Quantitative RT-PCR. Total RNA was isolated from PC12 cells using Trizol. Extracted RNA $(5 \mu \mathrm{g})$ was reverse transcribed with Superscript II, using oligo-dt as the primer, for $75 \mathrm{~min}$ at $43^{\circ} \mathrm{C}$, and the cDNA generated was used for real-time PCR. All PCR reactions were performed in a LightCycler (Roche Diagnostics, Laval, QC, Canada) using SYBR green PCR reagents in a final volume of $10 \mu \mathrm{L}$. Each 


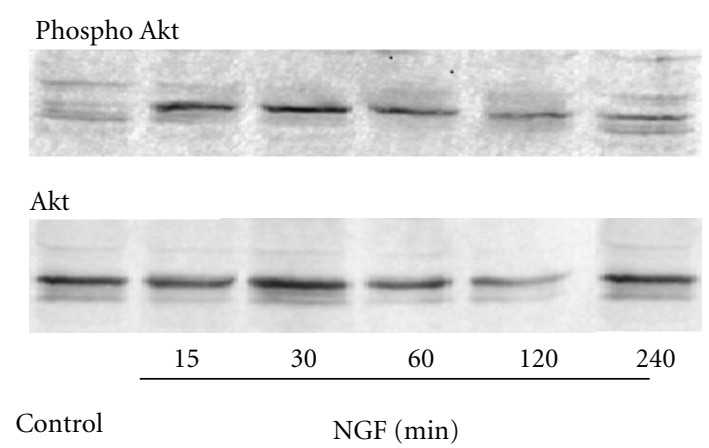

(a)

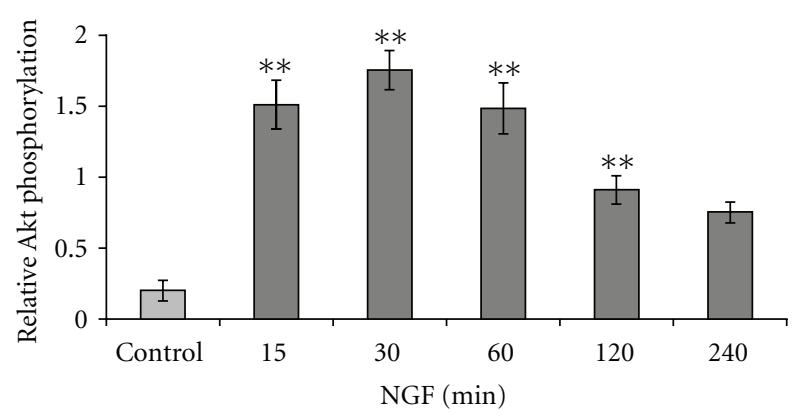

(b)

FIGURE 1: Temporal pattern for phosphorylation of Akt in NGF-treated PC12 cells. (a) Representative immunoblots of protein lysates from control (untreated) and NGF- $(50 \mathrm{ng} / \mathrm{mL})$ treated PC12 cells separated by SDS-PAGE, transferred to nitrocellulose membranes. Phosphorylated and nonphosphorylated forms of Akt were detected by incubating membranes with phosphorylation-specific and nonphosphorylation-dependent antibodies, and the primary antibodies used are identified above each panel. (b) Densitometric analysis of phosphorylated Akt normalized to total Akt levels. Treatment with NGF significantly increased Akt activation following $15 \mathrm{~min}, 30 \mathrm{~min}, 1 \mathrm{~h}$, and $2 \mathrm{~h}\left({ }^{* *} \mathrm{P}<0.01\right)$ of treatment. This figure is representative of immunoblots obtained from 5 independent experiments.

cycle began with an initial activation phase at $95^{\circ} \mathrm{C}$ for $15 \mathrm{~min}$ followed by 45 cycles of $15 \mathrm{~s}$ at $95^{\circ} \mathrm{C}, 20 \mathrm{~s}$ at $55^{\circ} \mathrm{C}$, and $15 \mathrm{~s}$ at $72^{\circ} \mathrm{C}$. The primers used to amplify the various NOS isoforms and the house keeping gene beta- 2 microglobulin were eNOS forward: $5^{\prime}$ agc tgt get ggc ata cag aa $3^{\prime}$, eNOS reverse: $5^{\prime}$ ggc tgc agt cct ttg atc tc $3^{\prime}$, iNOS forward: $5^{\prime}$ atg tgg cta cca ctt tga ag $3^{\prime}$, iNOS reverse: $5^{\prime}$ agg gec aga tgc tgt aac tc $3^{\prime}$, nNOS forward: $5^{\prime}$ ctg caa agc cet aag tcc ag $3^{\prime}$, nNOS reverse: $5^{\prime}$ agt gtt cct ctc ctc cag ca $3^{\prime}$, beta- 2 microglobulin forward: $5^{\prime}$ tga ccg tga tct ttc tgg gtg $3^{\prime}$ and beta- 2 microglobulin reverse: $5^{\prime}$ atc tga ggt ggg tgg aac ctg $3^{\prime}$.

2.7. Data Analysis. Immunoblots were scanned with the STORM 860 (Molecular Dynamics, subsidiary of Amersham) and the phospho- and total Akt bands visualized were analyzed densitometrically using Imagequant software (Molecular Dynamics). Data were calculated as the ratio of arbitrary densitometric units of phosphorylated Akt normalized to values obtained for total Akt bands from the same sample. Real-time PCR analysis was carried out using RelQuant software (Roche) and NOS isoform levels were quantified relative to beta- 2 microglobulin levels within the same sample. Data are presented as the mean \pm SEM. All data were assessed for normality and homogeneity of variance (Bartlett's test) and parametric statistical analysis was performed using a randomized one-way ANOVA followed by Dunnet's test to determine which groups were significantly different. For samples that did not pass the Bartlett's test, nonparametric statistical analysis was performed using the Kruskal-Wallis test followed by Dunn's multiple comparisons test. Mean values were considered different if $P<0.05$.

\section{Results}

3.1. Activation of Akt by NGF in PC12 Cells. Activation of Akt was assessed by immunoblot analysis, using antibodies specific for the phosphorylated (activated) form and the total level of Akt present. First, we established a temporal profile for activation of Akt by NGF treatment. Figure 1(a) (upper panel) illustrates the pattern of Akt activation by $50 \mathrm{ng} / \mathrm{mL}$ NGF on blots probed with phospho-Akt antibody; lysates obtained from untreated PC12 cells exhibited little or no Akt phosphorylation. There was a rapid increase in phospho-Akt levels with activation observed in samples obtained from cells treated with NGF from $15 \mathrm{~min}$ to $120 \mathrm{~min}$.

Ratios for densitometric analysis of phospho-Akt (normalized to total Akt) displayed as a function of NGF treatment time were calculated to quantify the activation profile for Akt. There was a significant increase in the level of phospho-Akt following 15, 30, 60, and $120 \mathrm{~min}$ exposure to NGF (Figure 1(b); ${ }^{*} P<0.01$ ), with the maximal increase being observed after $30 \mathrm{~min}$ of treatment. Following $240 \mathrm{~min}$ of NGF exposure, phospho Akt levels approached control values.

3.2. Activation of Akt by NGF in IMR32 Cells. The temporal profile for activation of Akt in IMR32 cells was shorter in duration as compared to what was observed in PC12 cells. Figure 2(a) (upper panel) illustrates the pattern of Akt activation by $50 \mathrm{ng} / \mathrm{mL}$ NGF on blots probed with phosphoAkt antibody. Lysates obtained from untreated IMR32 cells exhibited little Akt phosphorylation. There was a rapid increase in phospho-Akt levels with activation observed in samples obtained from cells treated with NGF for $15 \mathrm{~min}$. This activation appeared to be reduced following $30 \mathrm{~min}$ of NGF treatment and at subsequent time points, phosphoAkt levels appeared to be similar to that observed in control samples.

Ratios for densitometric analysis of phospho-Akt (normalized to total Akt) displayed as a function of NGF treatment time were calculated to quantify the activation profile for Akt in IMR32 cells. There was a significant and maximal increase in the level of phospho-Akt following 15 min of exposure to NGF (Figure 2(b); $* * * P<0.001$ ). Although phospho-Akt levels were consistently higher 


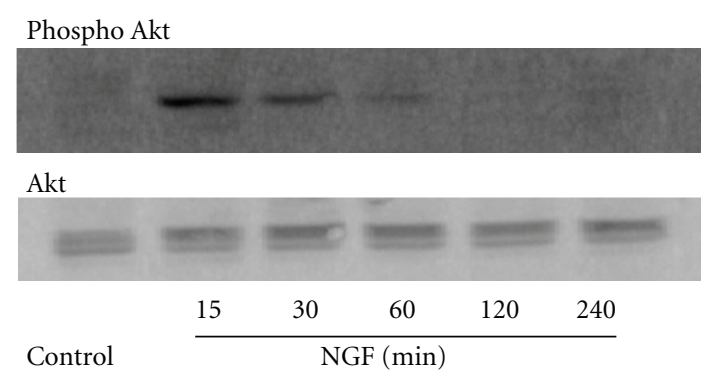

(a)

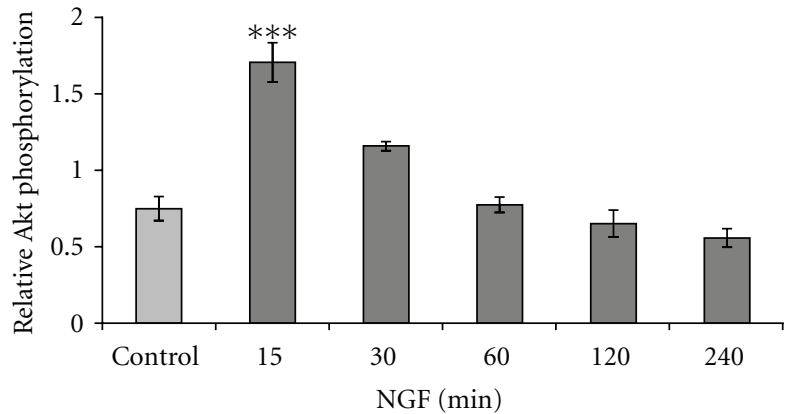

(b)

FIGURE 2: Temporal pattern for phosphorylation of Akt in NGF-treated IMR32 cells. (a) Representative immunoblots of protein lysates from control (untreated) and NGF- $(50 \mathrm{ng} / \mathrm{mL})$ treated PC12 cells separated by SDS-PAGE, transferred to nitrocellulose membranes. Phosphorylated and nonphosphorylated forms of Akt were detected by incubating membranes with phosphorylation-specific and nonphosphorylation-dependent antibodies, and the primary antibodies used are identified above each panel. (b) Densitometric analysis of phosphorylated Akt normalized to total Akt levels. NGF significantly increased Akt activation following 15 min of treatment $(* * * P<0.001)$. This figure is representative of immunoblots obtained from 6 independent experiments.

following $30 \mathrm{~min}$ of NGF treatment, this apparent increase was not statistically significant. Following 60, 120, and 240 min of NGF exposure, phospho-Akt levels were not different from control values.

\subsection{Effect of NOS Inhibitors on NGF-Mediated Activation of} Akt. To identify the mechanisms through which NO is modulating NGF signaling, the effects of NOS inhibitors on NGFmediated activation of Akt were examined. A representative western blot of phosphorylated Akt from control (untreated) or NGF-treated PC12 cells in the presence or absence of NOS inhibitors is shown in Figure 3. PC12 cells were treated with $20 \mathrm{mM}$ L-NAME or $2.0 \mathrm{mM}$ S-MIU in the presence and absence of $50 \mathrm{ng} / \mathrm{mL}$ of NGF. There was little or no phosphoAkt detected in samples obtained from untreated or NOS inhibitor-treated cells (Figures 3(a) and 3(c)). In the presence of L-NAME, the level of NGF-induced Akt phosphorylation appeared similar to that observed following treatment with NGF alone. In comparison, pretreatment of PC12 cells with S-MIU appeared to enhance the phosphorylation of Akt at later NGF treatment time points.

Densitometric analysis (Figures 3(b) and 3(d)) revealed there was no difference in Akt phosphorylation detected in samples obtained from control or NOS-inhibitor-treated cells. Similarly, activation of Akt in samples obtained from cells treated with NGF in the presence of L-NAME did not show any significant difference from that of samples treated with NGF alone at all treatment time points. Under both treatment conditions, there was a significant increase in Akt activation compared to control levels following 15, 30, 60, and $120 \mathrm{~min}$ of NGF treatment (Figure $3(\mathrm{~b}),{ }^{*} P<0.05$, $\left.{ }^{* *} P<0.01,{ }^{* * *} P<0.001\right)$. In contrast, in the presence of S-MIU, the maximal increase in Akt activation was observed following $60 \mathrm{~min}$ of treatment with NGF as compared to $30 \mathrm{~min}$ in the presence of NGF alone (Figure 3(d)). In addition, in the presence of S-MIU, the NGF-mediated increase in Akt activation was significantly higher at the $120 \mathrm{~min}$ time point, when compared with NGF treatment alone.
Similar results were obtained from IMR32 cells treated with NGF in the presence or absence of NOS inhibitors. A representative western blot of phosphorylated Akt from control (untreated) or $50 \mathrm{ng} / \mathrm{mL}$ NGF-treated IMR32 cells in the presence or absence of NOS inhibitors $(20 \mathrm{mM} \mathrm{L-NAME}$ or $2.0 \mathrm{mM}$ S-MIU) is shown in Figure 4(a). In the presence of L-NAME or S-MIU, NGF appeared to activate Akt following 15 and 30 min of treatment.

Densitometric analysis (Figures 4(b) and 4(c)) revealed there was no difference in Akt phosphorylation measured from control samples and lysates obtained from cells treated with either L-NAME or S-MIU alone. Under both treatment conditions, there was a significant increase in Akt phosphorylation following $15 \mathrm{~min}$ of NGF treatment $\left({ }^{* *} P<0.01\right.$, $* * * P<0.001)$, and there was no difference in the activation of Akt in the presence or absence of either inhibitor. In contrast to PC12 cells, both L-NAME and S-MIU appeared to prolong the activation of Akt, as there was a significant increase in Akt phosphorylation following $30 \mathrm{~min}$ of NGF treatment in the presence of NGF and NOS inhibitor $\left({ }^{*} P<\right.$ 0.01 ) but not following treatment with NGF alone.

\subsection{Effect of MEK Inhibition on NGF-Mediated Activation} of Akt. Since NO modulates the duration of NGF-mediated MAP kinase activation in PC12 cells [21], the effect of MEK inhibition on NGF-induced Akt phosphorylation was evaluated. Representative immunoblots of phosphorylated and total Akt levels from PC12 and IMR32 cells treated with NGF in the presence or absence of $50 \mu \mathrm{M}$ U0126 are depicted in Figure 5(a). Densitometric analysis of Akt activation is presented in Figures 5(b) (PC12 cells) and 5(c) (IMR32 cells). In the presence of U0126, the NGFmediated phosphorylation of Akt was enhanced in both cell lines. In U0126-treated PC12 cells, NGF increased Akt phosphorylation for at least $2 \mathrm{~h}$ (Figure 5(b), ${ }^{*} P<0.05$ for $60 \mathrm{~min},{ }^{*} P<0.01$ for 15 to $120 \mathrm{~min}$ ) and the NGFmediated increase in Akt activation was significantly higher at the $2 \mathrm{~h}$ time point, when compared with NGF treatment 


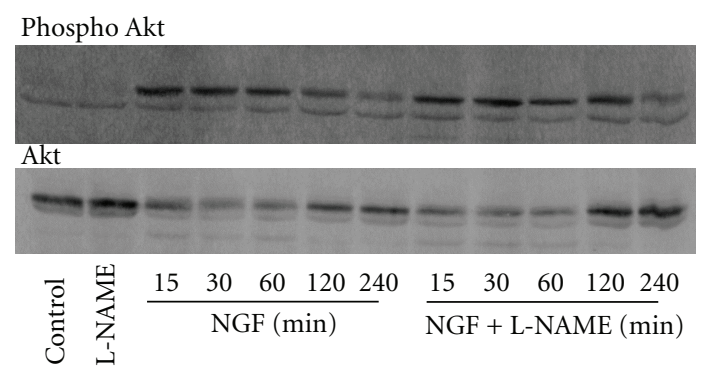

(a)

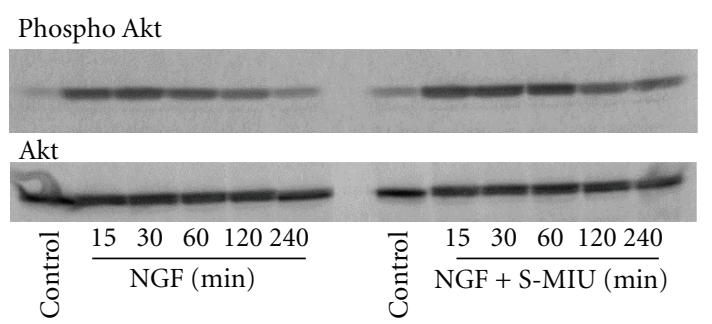

(c)

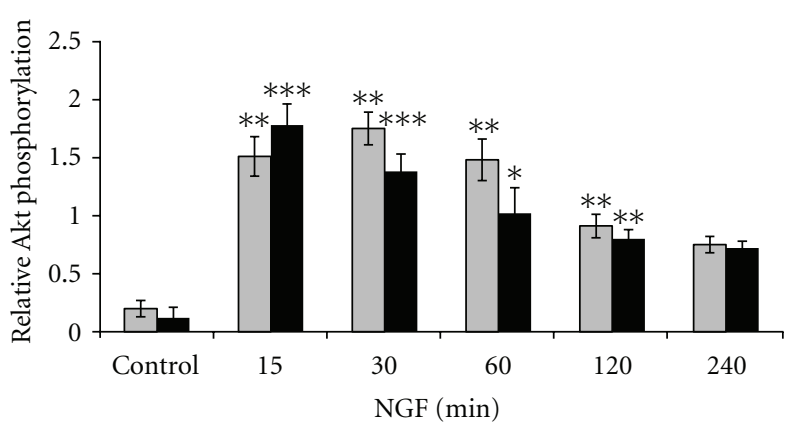

$\square$ NGF
- NGF + L-NAME

(b)

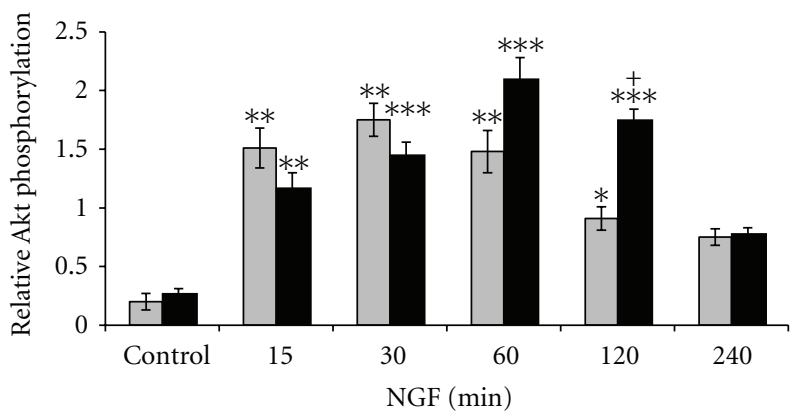

口 NGF

- S-MIU

(d)

FIgURE 3: Pattern of Akt phosphorylation in PC12 cells exposed to NGF in the presence or absence of NOS inhibitors. Cells were pretreated with NOS inhibitor $2 \mathrm{~h}$ prior to treatment with NGF. Representative immunoblots of lysates obtained from control and $20 \mathrm{mM}$ L-NAME (a) or $2.0 \mathrm{mM}$ S-MIU (c) in the presence or absence of NGF. Phosphorylated and nonphosphorylated forms of Akt are identified by the primary antibody indicated above each panel. Densitometric analysis of phosphorylated Akt normalized to total Akt levels in cells treated with NGF in the presence or absence of L-NAME (b) or S-MIU (d). NGF treatment significantly increased Akt phosphorylation above control levels in the presence or absence of NOS inhibitors $\left({ }^{*} P<0.05,{ }^{* *} P<0.01,{ }^{* *} P<0.001\right)$, and this increase was significantly higher in cells treated with NGF in combination with S-MIU as compared to those treated with NGF alone $\left({ }^{+} P<0.05\right)$. This figure is representative of immunoblots obtained from 5 or 6 independent experiments.

alone. In the presence or absence of U0126, the maximal increase in Akt activation in IMR32 cells occurred following 15 min of treatment with NGF $(* * P<0.01$ for NGF and $\mathrm{U} 0126$ and ${ }^{* * *} P<0.001$ for NGF alone), and Akt activation in the presence of U0126 was significantly higher at the $30 \mathrm{~min}$ time point $\left({ }^{*} P<0.01\right)$, compared with NGF treatment alone (Figure 5(c)). Although the levels of phosphorylated Akt were consistently higher following 60 min of treatment with NGF in the presence of U0126, this apparent increase was not statistically significant.

3.5. Effect of NOS Inhibition on NOS mRNA Levels. Since Akt activation is required for the NGF-mediated increase in eNOS levels [2], the relationship between enhanced Akt activation via NOS inhibition and NOS isoform expression was examined. PC12 cells were treated with $50 \mathrm{ng} / \mathrm{mL}$ NGF for $48 \mathrm{~h}$ either alone or in combination with $2.0 \mathrm{mM}$ S-MIU.
Using primers that detected eNOS, real-time PCR analysis revealed an increase in the steady-state levels of eNOS mRNA following treatment with NGF alone $\left({ }^{*} P<0.05\right)$ and this increase was prevented in cells pretreated with S-MIU (Figure 6(a)). Similarly, there was a significant increase in steady-state iNOS levels following $48 \mathrm{~h}$ of treatment with NGF $\left({ }^{*} P<0.05\right)$ and no difference in relative iNOS mRNA levels between control cells and those treated with S-MIU alone or in the presence NGF (Figure 6(b)). In contrast, S-MIU did affect the steady-state levels of nNOS mRNA (Figure 6(c)). Compared to control cells, there was a significant increase in relative nNOS mRNA levels following treatment with NGF alone or in combination with S-MIU $(* P<$ $0.05)$, and steady-state nNOS levels measured from cells treated with NGF in combination with S-MIU were significantly higher than those following treatment with NGF alone $\left({ }^{+} P<0.05\right)$. 

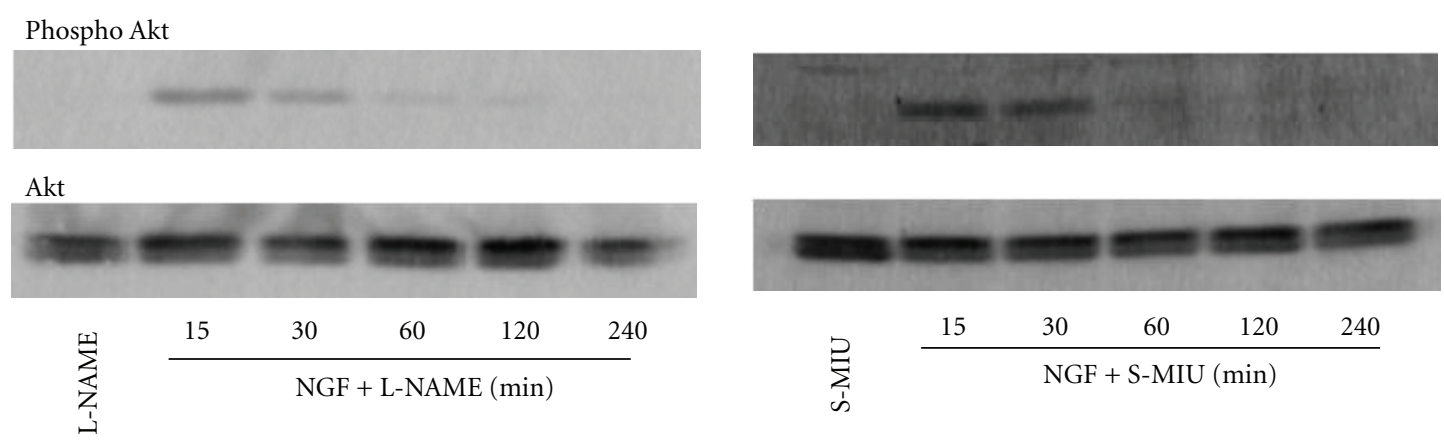

(a)

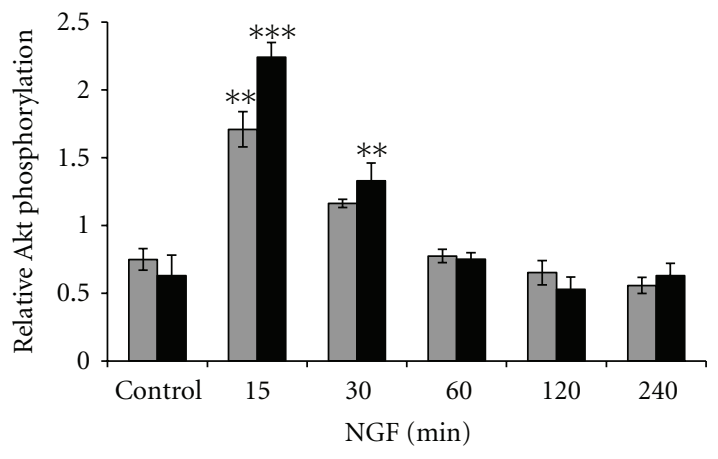

๑ NGF

- NGF + L-NAME

(b)

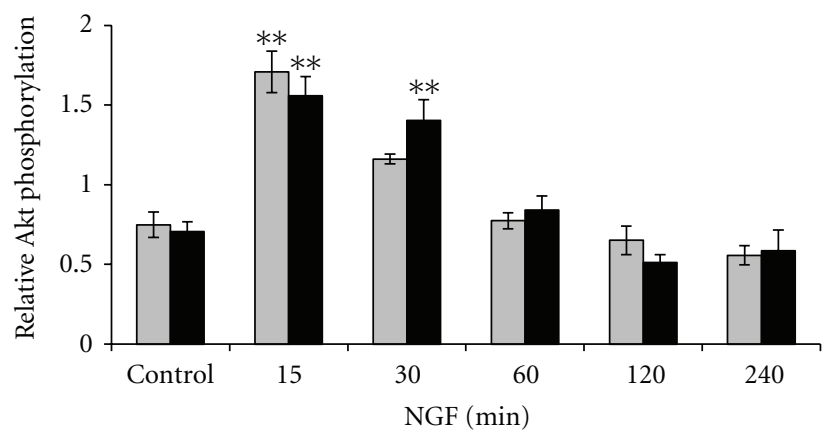

$\square$ NGF

- NGF + S-MIU

(c)

FIGURE 4: Pattern of Akt phosphorylation in IMR32 cells exposed to NGF in the presence or absence of NOS inhibitors. Cells were pretreated with NOS inhibitor $1 \mathrm{~h}$ prior to treatment with NGF. (a) Representative immunoblots of lysates obtained from control and $20 \mathrm{mM}$ L-NAME or 2.0 mM S-MIU in the presence or absence of NGF. Phosphorylated and nonphosphorylated forms of Akt are identified by the primary antibody indicated above each panel. Densitometric analysis of phosphorylated Akt normalized to total Akt levels in cells treated with NGF in the presence or absence of L-NAME (b) or S-MIU (c). NGF treatment significantly increased Akt phosphorylation above control levels in the presence or absence of NOS inhibitors $\left({ }^{*} P<0.05,{ }^{* *} P<0.01,{ }^{* * *} P<0.001\right)$. This figure is representative of immunoblots obtained from 6 independent experiments.

\section{Discussion}

In the present study, we provide evidence that $\mathrm{NO}$ modulates the NGF-induced activation of Akt. We demonstrated that the iNOS-selective inhibitor S-MIU did not result in an alteration in the level of initial NGF-mediated phosphorylation of Akt, but did increase the level or duration of activation of Akt in both PC12 and IMR32 cells. While the NOS inhibitor L-NAME had no effect on the NGFmediated phosphorylation of Akt in PC12 cells, prolonged Akt activation was observed in IMR32 cells. These studies demonstrate that NO modulates the activation of Akt by NGF. Since NOS inhibitors reduce the duration of activation of MAP kinase in PC12 cells [21], we investigated the effects 


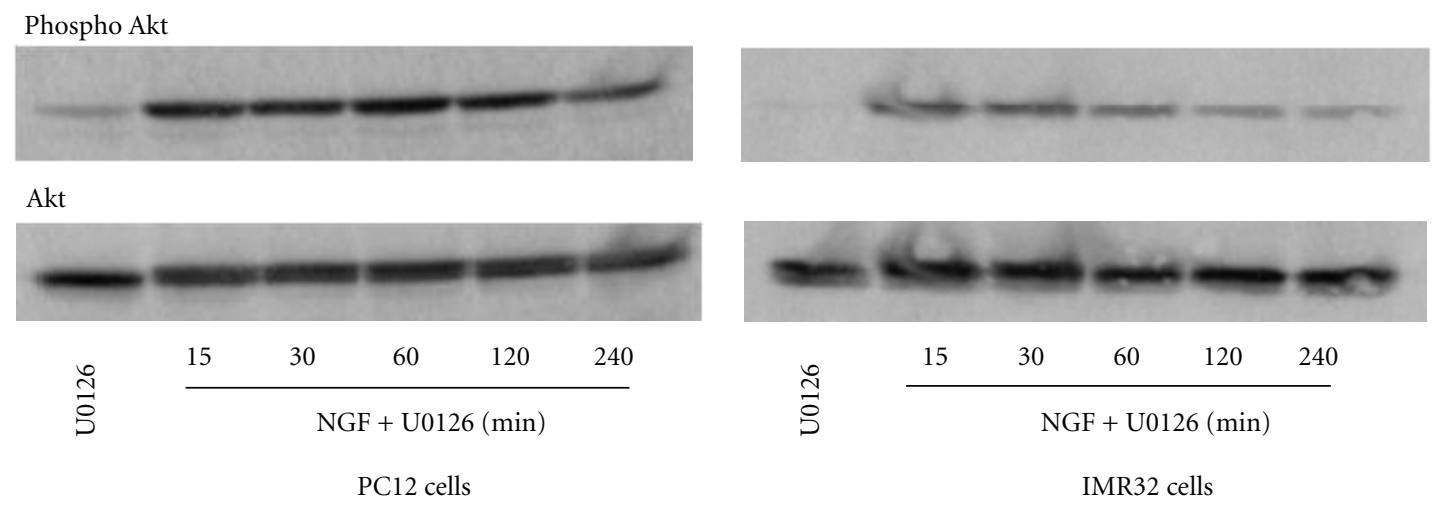

(a)

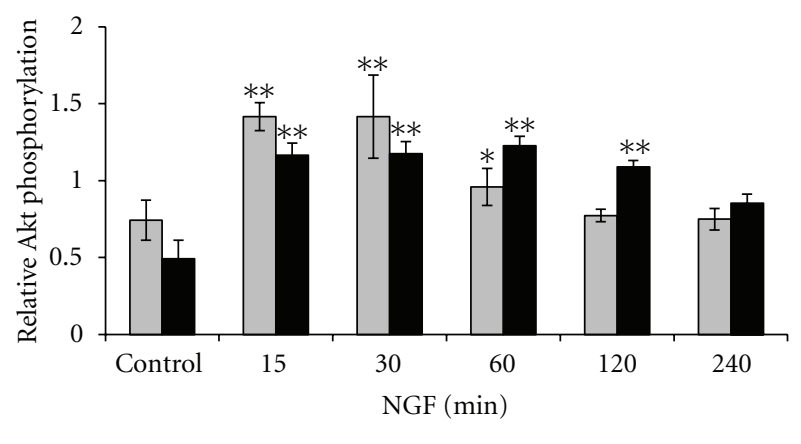

$\square$ NGF

- NGF + U0126

(b)

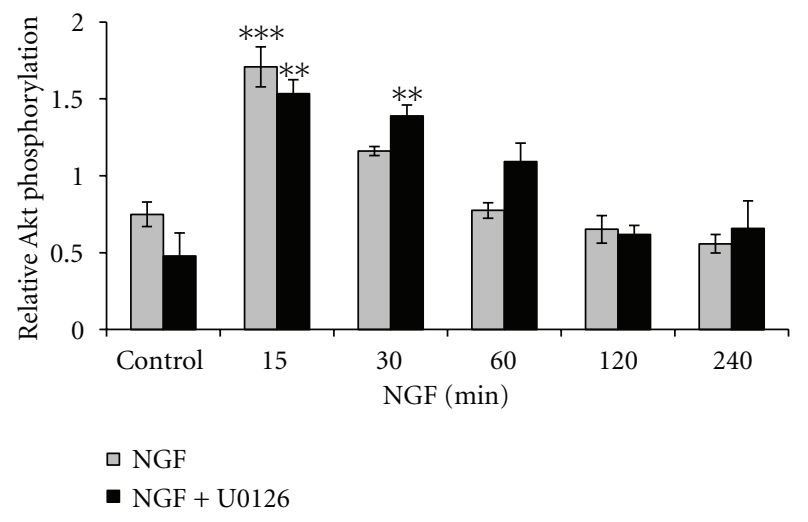

(c)

FIgure 5: Pattern of Akt phosphorylation in PC12 and IMR32 cells exposed to NGF in the presence or absence of U0126. Cells were pretreated with inhibitor $1 \mathrm{~h}$ prior to treatment with NGF. (a) Representative immunoblots of lysates obtained from PC12 or IMR32 cells grown in the presences of $50 \mu \mathrm{M}$ U0126 following treatment with NGF $(50 \mathrm{ng} / \mathrm{mL})$ for 15 to 240 min. Phosphorylated and nonphosphorylated forms of Akt are identified by the primary antibody indicated above each panel. Densitometric analysis of phosphorylated Akt normalized to total Akt levels in PC12 (b) and IMR32 (c) cells treated with NGF in the presence or absence of U0126. NGF treatment significantly increased Akt phosphorylation above control levels in the presence or absence of U0126 (** $P<0.01$, $\left.{ }^{* * *} P<0.001\right)$. This figure is representative of immunoblots obtained from 6 independent experiments.

of the MAP kinase inhibitor, U0126, on the NGF-mediated activation of Akt. In both cell lines, U0126 prolonged the activation of Akt, suggesting the modulation of Akt activation by NO may in part, be mediated by the effects of NGF on the MAP kinase signaling pathway. Treatment of PC12 cells with S-MIU in combination with NGF prevented the NGF-mediated increase in steady-state eNOS and iNOS mRNA levels but increased relative nNOS mRNA levels above that observed following treatment with NGF alone suggesting that in addition to differentially modulating NGFTrkA signaling pathways, NO also differentially affects NGFmediated gene expression. 


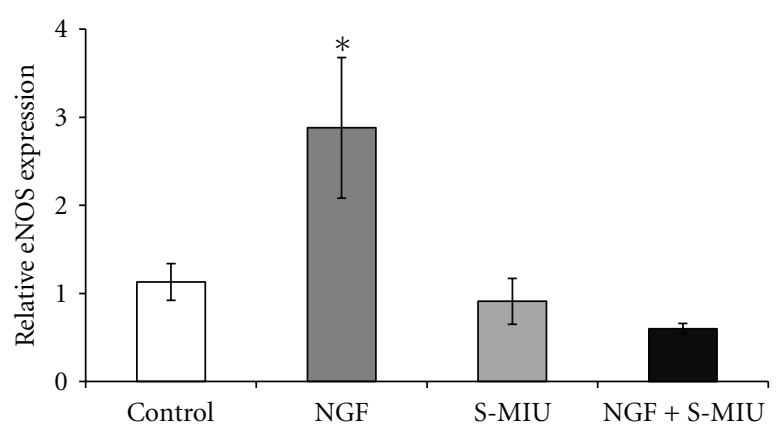

(a)

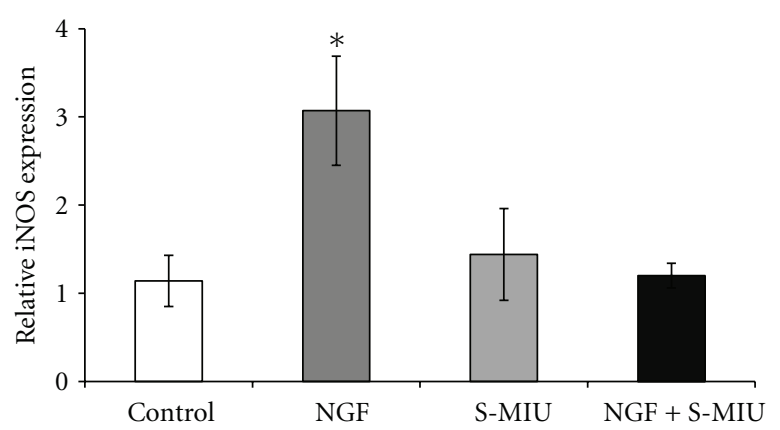

(b)

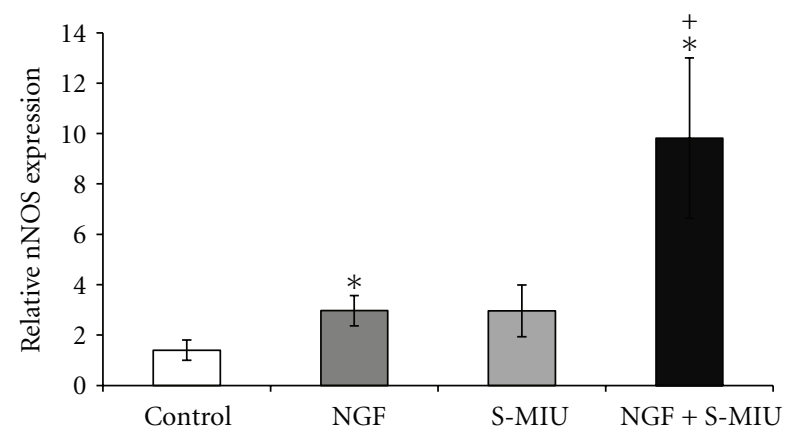

(c)

FIGURE 6: Analysis of steady-state NOS mRNA expression. Real-time PCR analysis of eNOS (a), iNOS (b), and nNOS (c) mRNA relative to beta- 2 microglobulin levels following treatment with $50 \mathrm{ng} / \mathrm{mL}$ NGF in the presence or absence of $2.0 \mathrm{mM}$ S-MIU. Treatment with NGF for $48 \mathrm{~h}$ resulted in a statistically significant $\left({ }^{*} P<0.05\right)$ increase in the steady-state levels of all three isoforms of NOS. Pretreatment with S-MIU prevented the NGF-mediated increase in eNOS and iNOS expression but increased relative nNOS mRNA levels above those observed following treatment with $\mathrm{NGF}$ alone $\left({ }^{+} P<0.05\right)$. This figure depicts data from 5 independent experiments.

Both IMR32 and PC12 cells have been used as cholinergic neuron models; however, NGF-TrkA signaling and cholinergic gene expression in IMR32 cells has not been well characterized. We, therefore, first investigated the temporal profile of NGF-induced Akt activation in both PC12 and IMR32 cell lines. In both cell lines, phosphorylation of Akt occurs within 15 min of NGF treatment. In PC12 cells, this level of phosphorylation is sustained for at least $60 \mathrm{~min}$, while in IMR32 cells, the activation of Akt decreases following 30 min of NGF treatment. While the reason for the difference in the temporal profile of Akt activation in these two cell lines is not known, it is possible that these different durations in the activation phase of Akt mediate different physiological functions of NGF in these two cell lines. Several reports have demonstrated that NGF increases ChAT levels in PC12 cells [4, 25-27]; however, this effect of NGF has not been described in IMR32 cells. This potential difference could in part be due to differences in the levels or duration of activation of NGF-TrkA signaling pathways in these two cell lines.

We reported previously that NO modulates NGFmediated increases in the levels of ChAT [4] and APP [3] and the activation profile of the MAP kinase pathway [21] in PC12 cells. To further characterize the role of NO in NGF signaling, the present study evaluated the effects of NOS inhibitors on NGF-mediated activation of the Akt signaling pathway in PC12 and IMR32 cells. Since the effects of NOS inhibitors have not been investigated in IMR32 cells, the inhibitors and doses selected were based on our previous findings in the PC12 cell line. In this cell line, relatively high doses $(\mathrm{mM})$ of L-NAME are routinely used [5, 29], likely due to high arginine levels in the culture media, and we determined that $20 \mathrm{mM} \mathrm{L-NAME}$ is required to attenuate NGF-mediated increases in NOS activity, NO production [4], and gene expression [3, 4]. Similarly, 2.0 mM S-MIU prevents NGF-mediated prolonged MAP kinase activation [21], elevations in APP expression [3], and increases in NOS activity, NO production, and ChAT expression [4], while lower doses do not. Therefore, doses of $20 \mathrm{mM} \mathrm{L-NAME}$ and $2.0 \mathrm{mM}$ S-MIU were used in the present study. In PC12 cells, in comparison to control, NGF caused a significant increase in phospho-Akt levels at 15, 30,60, and $120 \mathrm{~min}$ and by 240 min these levels returned to control. When PC12 cells were pretreated with L-NAME, there was no change in the NGF-mediated activation profile of Akt as compared to NGF alone. In contrast to L-NAME, S-MIU did alter the profile of Akt phosphorylation. S-MIU had no effect on control Akt activation but in the presence of NGF, increased the level of Akt phosphorylation normally seen with $2 \mathrm{~h}$ of NGF treatment alone. Supporting data was obtained with IMR32 cells pretreated with NOS inhibitors; however, in this cell line both L-NAME and S-MIU prolonged the duration of Akt activation. The reason for the differential action of these inhibitors in PC12 and IMR32 cells is not clear; however, it is possible that these cell lines express different NOS isoforms.

While PC12 cells express all three NOS isoforms $[4,5]$, it is not known which isoforms are present in IMR32 cells. 
The differential expression of NOS isoforms could result in differences in the level or location of NO produced in these cell lines following NGF treatment. We demonstrated previously that, while both inhibitors decreased NOS activity in PC12 cells, S-MIU inhibited NGF-mediated NO production (measured by DAF2 fluorescence) to a greater extent than LNAME did [4]. These data suggest that even at high doses, L-NAME may not completely block the production of NO by iNOS and that S-MIU may be inhibiting multiple NOS isoforms. If NO production from constitutive NOS isoforms plays a larger role in the modulation of Akt activation in the IMR32 cell line and iNOS is a more important contributor in PC12 cells, then L-NAME would modulate NGF-TrkA signaling differently in these two cell lines. The ability of NOS inhibitors to enhance the phosphorylation of Akt appears to be in contrast to previous findings that NO donor drugs activate Akt in PC12 cells [22]. This discrepancy in the action of NO could be due to differences in the level of NO produced under the two treatment conditions or the activation of additional signaling pathways following NGF treatment that does not occur following exposure to $\mathrm{NO}$ donor drugs. While NO released from these compounds could result in Akt phosphorylation, the activation of NO resulting from NGF treatment does not appear to play a role in the initial activation of this signaling pathway in either cell line. In the present study, NOS inhibitors do not prevent the NGF-mediated phosphorylation of Akt, suggesting that NO is not necessary for this action of NGF. As well, since L-NAME and S-MIU did not alter the initial level of NGFmediated phosphorylation of Akt and did not inhibit the duration of activation, NO likely does not alter the activation of any upstream regulators of Akt.

The ability of NOS inhibitors to prolong Akt activation also appears to be in contrast to our previous findings that the NOS inhibitor S-MIU attenuated the prolonged phosphorylation of MAP kinase that is normally observed by exposure of PC12 cells to NGF [21]. To address the link between these two pathways, we assessed the effects of MAP kinase inhibition on NGF-mediated Akt activation. Interestingly, pretreatment of both PC12 and IMR32 cells with the MAP kinase inhibitor, U0126, resulted in increased levels of NGF-mediated Akt phosphorylation. This treatment model suggests that NGF-mediated activation of MAP kinase results in the subsequent inhibition of Akt activation.

The mechanism by which NO may be modulating Akt activation is not clear. In the present study, one or more of the TrkA signal transduction pathways could result in the NGF-mediated activation of NOS, leading to an increase in NO production. This increase in NO could modulate the function of other proteins or gene products that act to enhance MAP kinase activation [21] and inhibit Akt activation. Two possibilities include the activation of PKC and the modulation of protein kinase $\mathrm{G}$ activity. It has been reported that peroxynitrite and $\mathrm{NO}$ donors can activate certain isoforms of PKC in some cell types $[30,31]$ and that peroxynitritemediated phosphorylation of MAP kinase occurs in a MEKindependent but PKC-dependent manner [30]. Furthermore, in $\mathrm{PC} 12$ cells, $\mathrm{PKC}$ activation was reported to attenuate insulin-like growth factor-mediated Akt activation [32].
Taken together, these data suggest that NO-mediated activation of PKC could enhance MAP kinase phosphorylation and inhibit Akt activation. Ha and colleagues [22] reported that cGMP and activation of protein kinase $\mathrm{G}$ were necessary for the NO-mediated activation of Akt. Previously, we found that the NGF-mediated production of NO that modulated MAP kinase phosphorylation was not dependent on the activation of the cGMP-protein kinase G pathway [21]. This indicates that NO could be modulating Akt and MAP kinase differentially via cGMP-dependent and -independent pathways, respectively.

In PC12 cells, NGF-mediated activation of Akt is sustained for at least $2 \mathrm{~h}$; however, when NO production is inhibited, enhanced phosphorylation of Akt occurs. Similarly, the NGF-mediated activation profile of Akt in IMR32 cells is prolonged in the presence of NOS inhibitors. The ability of S-MIU to prolong Akt signaling following NGF treatment is opposite to our previous findings, that S-MIU attenuates the prolonged phosphorylation of MAP kinase in PC12 cells [21], blocks neurite outgrowth [3,4], and inhibits the enhanced levels of ChAT [4] and APP [3] normally observed following treatment with NGF. Since Akt signaling pathways play a role in PC12 cell differentiation [33], the prolonged activation of Akt by S-MIU should enhance this process rather than inhibit it. However, prolonged activation of the MAP kinase signaling cascade is essential for neurotrophin-mediated differentiation of PC12 cells [34], and the duration of activation of this signaling pathway by NGF is reduced in the presence of S-MIU. Since both NGFmediated neurite outgrowth and the NGF-enhanced levels of ChAT [4] and APP [3] observed in PC12 cells are attenuated by S-MIU, the modulation of Akt signaling by NO does not appear to affect the ability of PC12 cells to perform these functions. Interestingly, in PC12 cells, inhibition of either the MAP kinase or Akt pathway, by pretreatment with U0126 or LY29400, respectively, was enough to prevent the NGFmediated increase in APP protein levels, but neither inhibitor prevented the NGF-mediated neurite outgrowth to the same extent that S-MIU did [3]. This indicates that, while NO modulates both processes, there is differential regulation of NGF-mediated neurite outgrowth and gene expression in this cell line.

Both NO and NGF-mediated activation of TrkA signal transduction pathways are required for gene expression and neurite outgrowth. While NO modulates the activation profile of NGF-TrkA signal transduction pathways, the role of NO in NGF-TrkA signaling may be quite complicated since the activation of Akt and MAP kinase has been implicated in regulating NOS levels and NO production [35, 36]. We, therefore, examined the effects of NOS inhibition, which reduces the duration of NGF-mediated MAP kinase activation [21] and enhances Akt activation, on the mRNA levels of the individual NOS isoforms in the presence and absence of NGF. In the present paper, NGF increased the steadystate levels of all three isoforms of NOS in PC12 cells. The inhibition of NO production by S-MIU prevented the NGFmediated increase in eNOS and iNOS mRNA expression but enhanced the ability of NGF to increase relative nNOS mRNA levels. These findings were surprising since activation 
of the Akt signaling pathway has been reported to play a role in regulating eNOS expression [2] and MAP kinase pathway activation was found to be necessary for the NGF-mediated increase in nNOS expression in PC12 cells [35]. In contrast to these findings, our data appear to support a model in which the NO-mediated prolonged activation of MAP kinase contributes to the NGF-mediated increases in eNOS and iNOS mRNA levels rather than nNOS expression. However, the mechanisms involved in regulating the expression of NOS isoforms by S-MIU are complicated by the fact that this NOS inhibitor does not prevent the NGF-mediate activation of MAP kinase but instead reduces the duration of activation of this signaling pathway. A better understanding of the regulation of NGF signaling, NO production, and the link between these two processes and gene expression will be critical for our understanding of cell cycle arrest, morphological differentiation, neuron survival, and phenotypic maintenance.

This study provides evidence for the mechanisms of NGF-mediated Akt activation. Inhibition of NOS in either PC12 or IMR32 cells enhances the phosphorylation of Akt normally induced by NGF. In both cell lines, inhibition of MAP kinase signaling also increased the activation of Akt, suggesting that the modulation of NGF-induced Akt activation by NO may, in part, be mediated by the effects of NO on the MAP kinase signaling pathway. A better understanding of the effects of NO on signaling pathway activation may provide important information with respect to the role of $\mathrm{NO}$ in the regulation of gene expression in specific cell types.

\section{Abbreviations}

Ach: Acetylcholine

ANOVA: Analysis of variance

APP: Amyloid precursor protein

ChAT: Choline acetyltransferase

DMEM: Dulbecco's modified Eagle medium

eNOS: Endothelial nitric oxide synthase

FBS: $\quad$ Fetal bovine serum

iNOS: Inducible nitric oxide synthase

L-NAME: $\mathrm{N}^{\omega}$-nitro-L-arginine methylester

MAP: Mitogen-activated protein

MEK: $\quad$ MAP kinase kinase

MEM: Minimum essential medium

S-MIU: S-methylisothiourea

NGF: Nerve-growth-factor

NO: $\quad$ Nitric oxide

NOS: $\quad$ Nitric oxide synthase

nNOS: Neuronal nitric oxide synthase

PBS: $\quad$ Phosphate-buffered saline

PCR: $\quad$ Polymerase chain reaction

RT: $\quad$ Reverse transcriptase

SEM: $\quad$ Standard error of the mean

TBS: $\quad$ Tris-buffered saline.

\section{Acknowledgments}

These studies were supported by an operating grant from the Natural Sciences and Engineering Research Council of
Canada to B. E. Kalisch and an Ontario Graduate Scholarship to C. L. Cragg.

\section{References}

[1] D. R. Kaplan and R. M. Stephens, "Neurotrophin signal transduction by the Trk receptor," Journal of Neurobiology, vol. 25, no. 11, pp. 1404-1417, 1994.

[2] D. Fulton, J. P. Gratton, T. J. McCabe et al., "Regulation of endothelium-derived nitric oxide production by the protein kinase Akt," Nature, vol. 399, no. 6736, pp. 597-601, 1999.

[3] J. C. Binnington and B. E. Kalisch, "Nitric oxide synthase inhibitors modulate nerve growth factor-mediated regulation of amyloid precursor protein expression in PC12 cells," Journal of Neurochemistry, vol. 101, no. 2, pp. 422-433, 2007.

[4] B. E. Kalisch, N. A. Bock, W. L. Davis, and R. J. Rylett, "Inhibitors of nitric oxide synthase attenuate nerve growth factor-mediated increases in choline acetyltransferase expression in PC12 cells," Journal of Neurochemistry, vol. 81, no. 3, pp. 624-635, 2002.

[5] N. Peunova and G. Enikolopov, "Nitric oxide triggers a switch to growth arrest during differentiation of neuronal cells," Nature, vol. 375, no. 6526, pp. 68-73, 1995.

[6] Y. T. Phung, J. M. Bekker, O. G. Hallmark, and S. M. Black, "Both neuronal NO synthase and nitric oxide are required for PC12 cell differentiation: a cGMP independent pathway," Molecular Brain Research, vol. 64, no. 2, pp. 165-178, 1999.

[7] Y. Kim, R. Seger, C. V. Suresh Babu, S. Y. Hwang, and Y. S. Yoo, "A positive role of the PI3-K/Akt signaling pathway in PC12 cell differentiation," Molecules and Cells, vol. 18, no. 3, pp. 353359, 2004.

[8] R. J. Crowder and R. S. Freeman, "Phosphatidylinositol 3kinase and Akt protein kinase are necessary and sufficient for the survival of nerve growth factor-dependent sympathetic neurons," Journal of Neuroscience, vol. 18, no. 8, pp. 29332943, 1998.

[9] R. Yao and G. M. Cooper, "Requirement for phosphatidylinositol-3 kinase in the prevention of apoptosis by nerve growth factor," Science, vol. 267, no. 5206, pp. 2003-2006, 1995.

[10] B. Mayer, K. Schmidt, P. Humbert, and E. Bohme, "Biosynthesis of endothelium-derived relaxing factor: a cytosolic enzyme in porcine aortic endothelial cells $\mathrm{Ca}^{2+}$-dependently converts L-arginine into an activator of soluble guanylyl cyclase," Biochemical and Biophysical Research Communications, vol. 164, no. 2, pp. 678-685, 1989.

[11] A. M. Sheehy, Y. T. Phung, R. K. Riemer, and S. M. Black, "Growth factor induction of nitric oxide synthase in rat pheochromocytoma cells," Molecular Brain Research, vol. 52, no. 1, pp. 71-77, 1997.

[12] M. Sano, I. Sato-Suzuki, H. Fujita, I. Morita, M. Nagao, and S. Murota, "NO is not involved in the simvastatin induced cell division and differentiation in PC12 cells," Neuroscience Letters, vol. 243, no. 1-3, pp. 73-76, 1998.

[13] H. M. Lander, J. S. Ogiste, K. K. Teng, and A. Novogrodsky, "P21ras as a common signaling target of reactive free radicals and cellular redox stress," Journal of Biological Chemistry, vol. 270, no. 36, pp. 21195-21198, 1995.

[14] B. I. Kanterewicz, L. T. Knapp, and E. Klann, "Stimulation of p42 and p44 mitogen-activated protein kinases by reactive oxygen species and nitric oxide in hippocampus," Journal of Neurochemistry, vol. 70, no. 3, pp. 1009-1016, 1998.

[15] S. O. Kim, Y. Xu, S. Katz, and S. Pelech, "Cyclic GMPdependent and -independent regulation of MAP kinases by 
sodium nitroprusside in isolated cardiomyocytes," Biochimica et Biophysica Acta, vol. 1496, no. 2-3, pp. 277-284, 2000.

[16] M. Llansola, R. Sáez, and V. Felipo, "NMDA-induced phosphorylation of the microtubule-associated protein MAP-2 is mediated by activation of nitric oxide synthase and MAP kinase," European Journal of Neuroscience, vol. 13, no. 7, pp. 1283-1291, 2001.

[17] H. P. Monteiro, J. Gruia-Gray, T. M. Peranovich, L. C. de Oliveira, and A. Stern, "Nitric oxide stimulates tyrosine phosphorylation of focal adhesion kinase, SRC kinase, and mitogen-activated protein kinases in murine fibroblasts," Free Radical Biology and Medicine, vol. 28, no. 2, pp. 174-182, 2000.

[18] H. Y. Yun, M. Gonzalez-Zulueta, V. L. Dawson, and T. M. Dawson, "Nitric oxide mediates N-methyl-D-aspartate receptor-induced activation of p21ras," Proceedings of the National Academy of Sciences of the United States of America, vol. 95, no. 10, pp. 5773-5778, 1998.

[19] R. S. Jope, L. Zhang, and L. Song, "Peroxynitrite modulates the activation of p38 and extracellular regulated kinases in PC12 cells," Archives of Biochemistry and Biophysics, vol. 376, no. 2, pp. 365-370, 2000.

[20] P. Zhang, Y. Z. Wang, E. Kagan, and J. C. Bonner, "Peroxynitrite targets the epidermal growth factor receptor, Raf-1, and MEK independently to activate MAPK," Journal of Biological Chemistry, vol. 275, no. 29, pp. 22479-22486, 2000.

[21] B. E. Kalisch, C. S. Demeris, M. Ishak, and R. J. Rylett, "Modulation of nerve growth factor-induced activation of MAP kinase in PC12 cells by inhibitors of nitric oxide synthase," Journal of Neurochemistry, vol. 87, no. 6, pp. 1321-1332, 2003.

[22] K. S. Ha, K. M. Kim, Y. G. Kwon et al., "Nitric oxide prevents 6-hydroxydopamine-induced apoptosis in PC12 cells through cGMP-dependent PI3 kinase/Akt activation," FASEB Journal, vol. 17, no. 9, pp. 1036-1047, 2003.

[23] D. S. Hartman and C. Hertel, "Nerve growth factor-induced differentiation in neuroblastoma cells expressing TrkA but lacking p75 ${ }^{N G F R}$," Journal of Neurochemistry, vol. 63, no. 4, pp. 1261-1270, 1994.

[24] W. Wang, S. M. Dostaler, G. Lawrance, G. M. Ross, R. J. Riopelle, and K. E. Dow, "Effects of a peptide analogue of the amphiphilic domain of the common neurotrophin receptor on nerve growth factor-mediated motility of human neuroblastoma cells," Journal of Neurochemistry, vol. 70, no. 6, pp. 2327-2335, 1998.

[25] P. Kahle, M. Mangold, T. Kuwahara, R. Schubenel, and C. Hertel, "Protein kinase inhibitor H-7 differentially affects early and delayed nerve growth factor responses in PC12 cells," Journal of Neurochemistry, vol. 62, no. 2, pp. 479-488, 1994.

[26] B. Madziar, I. Lopez-Coviella, V. Zemelko, and B. Berse, "Regulation of cholinergic gene expression by nerve growth factor depends on the phosphatidylinositol-3'-kinase pathway," Journal of Neurochemistry, vol. 92, no. 4, pp. 767-779, 2005.

[27] J. L. Pongrac and R. J. Rylett, "NGF-induction of the expression of ChAT mRNA in PC12 cells and primary cultures of embryonic rat basal forebrain," Molecular Brain Research, vol. 62, no. 1, pp. 25-34, 1998.

[28] G. J. Southan, C. Szabo, and C. Thiemermann, "Isothioureas: potent inhibitors of nitric oxide synthases with variable isoform selectivity," British Journal of Pharmacology, vol. 114, no. 2, pp. 510-516, 1995.

[29] E. Satoh, I. Yasuda, T. Yamada, Y. Suzuki, and T. Ohyashiki, "Involvement of NO generation in aluminum-induced cell death," Biological and Pharmaceutical Bulletin, vol. 30, no. 8, pp. 1390-1394, 2007.
[30] S. Bapat, A. Verkleij, and J. A. Post, "Peroxynitrite activates mitogen-activated protein kinase (MAPK) via a MEKindependent pathway: a role for protein kinase C," FEBS Letters, vol. 499, no. 1-2, pp. 21-26, 2001.

[31] M. Liang and F. G. Knox, "Nitric oxide activates PKC $\alpha$ and inhibits $\mathrm{Na}^{+}-\mathrm{K}^{+}$-ATPase in opossum kidney cells," American Journal of Physiology, vol. 277, no. 6, pp. F859-F865, 1999.

[32] W. H. Zheng, S. Kar, and R. Quirion, "Stimulation of protein kinase C modulates insulin-like growth factor-1- induced Akt activation in PC12 cells," Journal of Biological Chemistry, vol. 275, no. 18, pp. 13377-13385, 2000.

[33] A. Markus, J. Zhong, and W. D. Snider, "Raf and Akt mediate distinct aspects of sensory axon growth," Neuron, vol. 35, no. 1, pp. 65-76, 2002.

[34] E. J. Huang and L. F. Reichardt, "Trk receptors: roles in neuronal signal transduction," Annual Review of Biochemistry, vol. 72, pp. 609-642, 2003.

[35] C. M. Schonhoff, D. A. Bulseco, D. M. Brancho, L. F. Parada, and A. H. Ross, "The Ras-ERK pathway is required for the induction of neuronal nitric oxide synthase in differentiating PC12 cells," Journal of Neurochemistry, vol. 78, no. 3, pp. 631639, 2001.

[36] A. Uruno, A. Sugawara, H. Kanatsuka et al., "Upregulation of nitric oxide production in vascular endothelial cells by alltrans retinoic acid through the phosphoinositide 3-kinase/Akt pathway," Circulation, vol. 112, no. 5, pp. 727-736, 2005. 

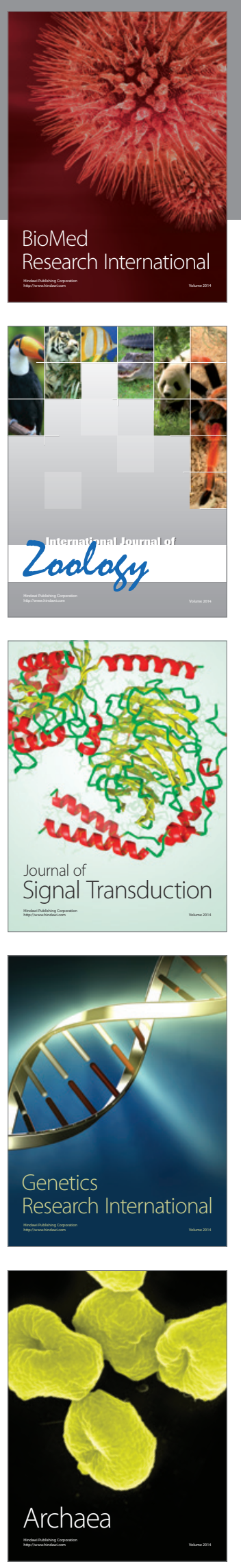
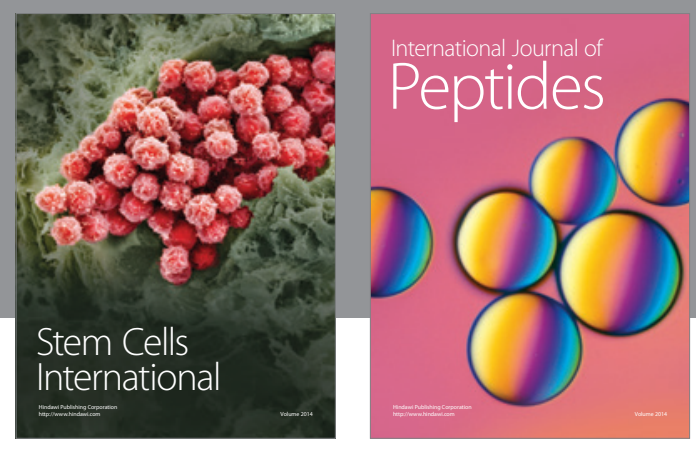

Submit your manuscripts at

http://www.hindawi.com
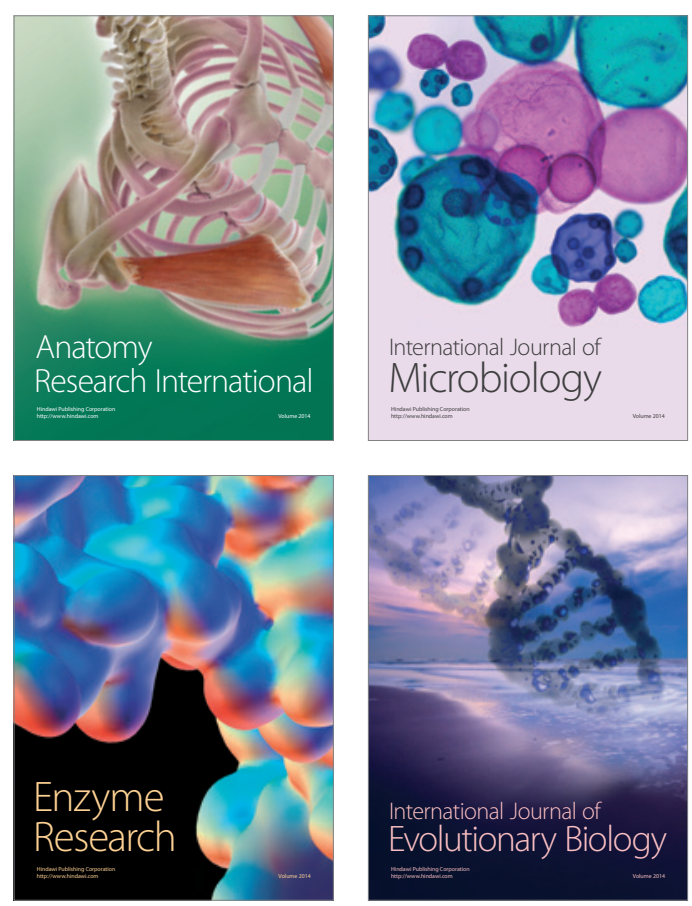
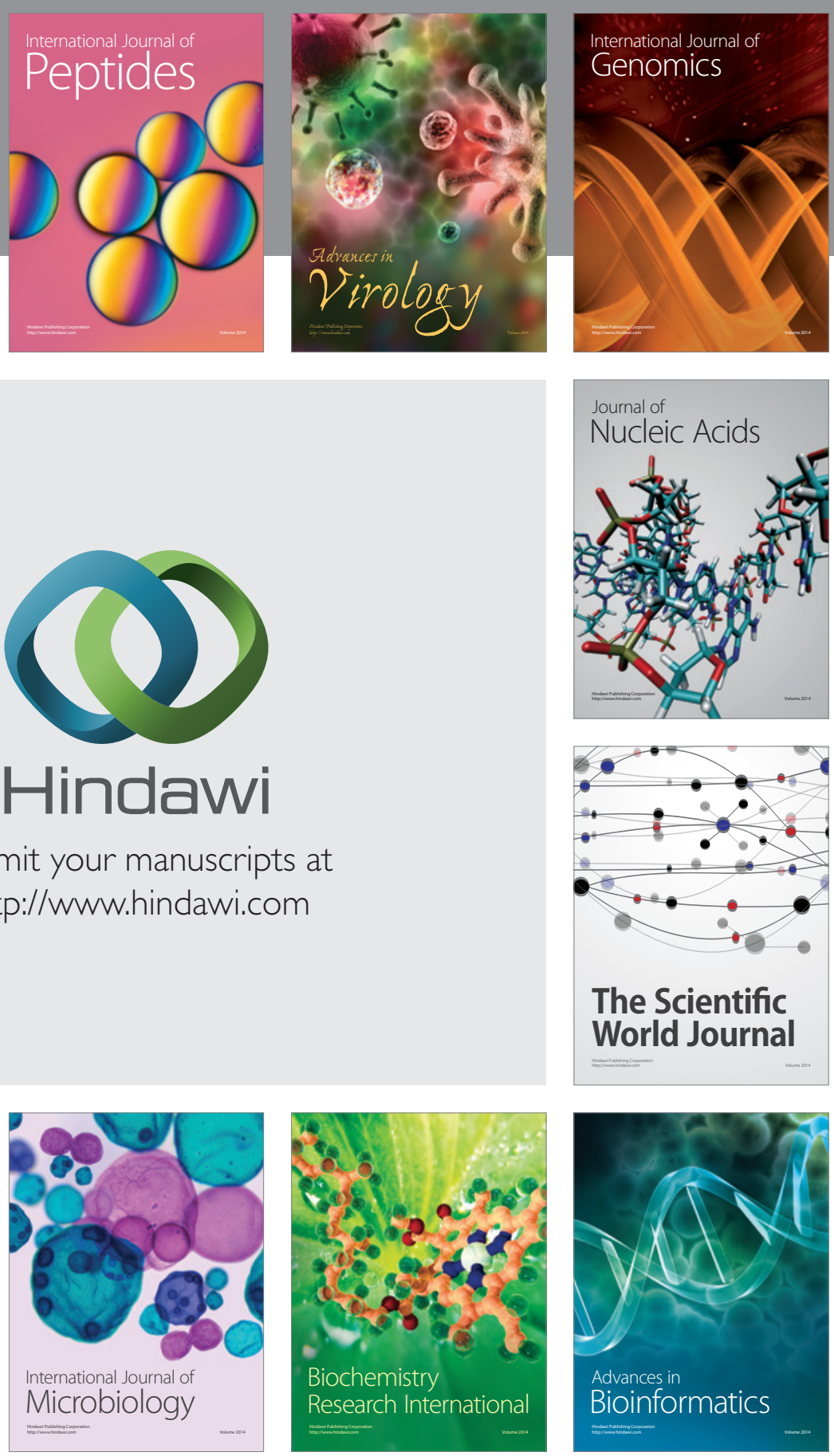

The Scientific World Journal
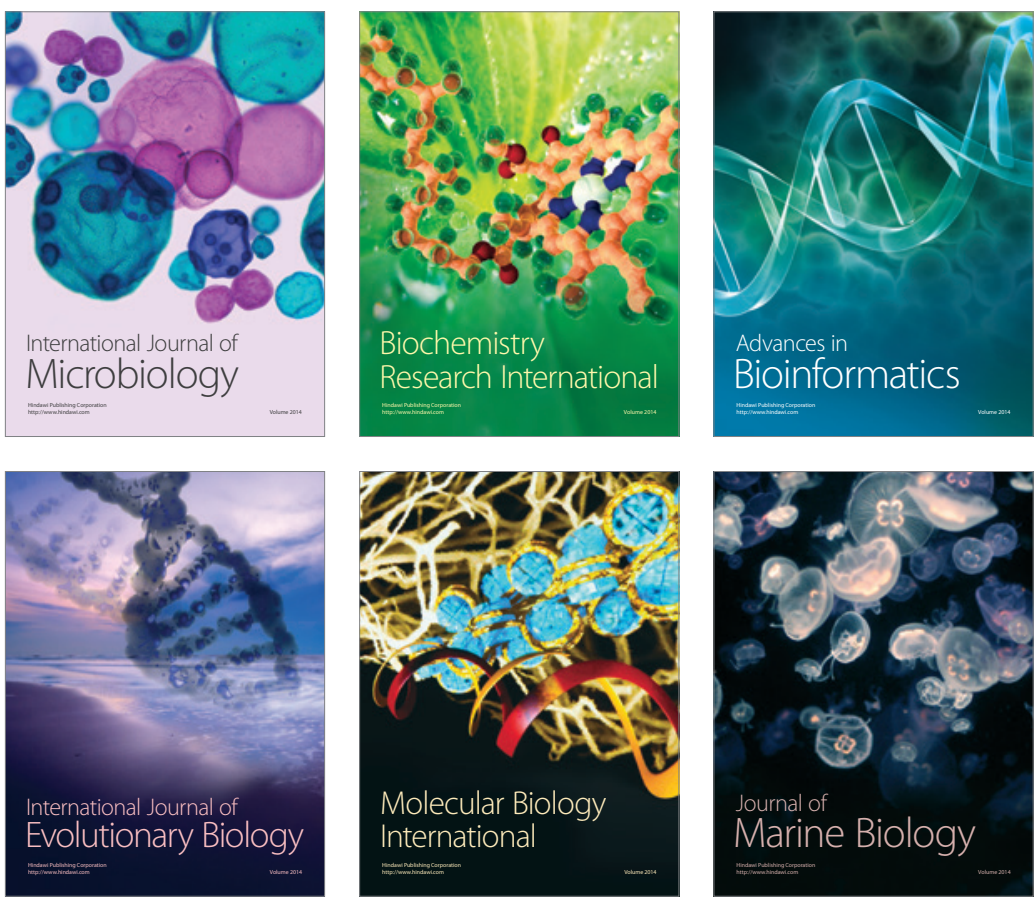